Current Research in Dentistry 3 (1): 7-17, 2012

ISSN 1949-0119

(C) 2012 Science Publications

\title{
Bonding of Resin Materials to All-Ceramics: A Review
}

\author{
Liang Chen and Byoung In Suh \\ Research and Development, Bisco Inc, \\ 1100 West Irving Park Road, Schaumburg, IL, 60193, USA
}

\begin{abstract}
Problem statement: All-ceramic materials, especially silica-based lithium disilicate and nonsilicate-based Zirconia, have become a topic of interest in the field of dentistry. It is still difficult to achieve a strong and durable resin-ceramic adhesion, especially resin-Zirconia bonding. Approach: The article reviews the current literature published in the past 5 years, focusing on the latest resin bonding techniques (including surface treatment, priming and cementation) for dental all-ceramic materials, especially Zirconia and lithium disilicate ceramics. A search of dental literature from PubMed and MEDLINE databases was conducted and the key words included Zirconia, lithium disilicate and bond. Titles and abstracts of the articles listed from search results were reviewed and evaluated for appropriateness. Results: The literature demonstrates that a variety of surface roughness, priming and cementation methods are available for improving resin-ceramic bonding. Conclusion: Available data suggest that the preferred bonding methods for silica-based ceramics are hydrofluoric acid-etching and subsequent silent treatments. The preferred protocol for Zirconia-resin bonding is the combination of surface roughness such as air-abrasion and treatment with a phosphate-containing Zirconia primer followed by cementation with a non-phosphate-containing resin cement.
\end{abstract}

Key words: Zirconia, lithium disilicate, surface treatment, phosphate monomer, primer

\section{INTRODUCTION}

There has been an increasing interest and demand in the use of all-ceramic materials due to their nonmetallic, biocompatible and improved esthetic features (Blatz et al., 2003; Conrad et al., 2007). The core materials of all-ceramics include silica-based glass ceramics, such as Lithium-disilicate $\left(2 \mathrm{SiO}_{2}-\mathrm{Li}_{2} \mathrm{O}\right)$, Leucite $\left(\mathrm{SiO}_{2}-\mathrm{Al}_{2} \mathrm{O}_{3}-\mathrm{K}_{2} \mathrm{O}\right)$ and Feldspathic $\left(\mathrm{SiO}_{2-}\right.$ $\left.\mathrm{Al}_{2} \mathrm{O}_{3}-\mathrm{Na}_{2} \mathrm{O}-\mathrm{K}_{2} \mathrm{O}\right)$ and silica-free high strength ceramics, such as Zirconia $\left(\mathrm{ZrO}_{2}\right)$ and Alumina $\left(\mathrm{Al}_{2} \mathrm{O}_{3}\right)$ (Conrad et al., 2007). Among the all-ceramic materials, Zirconia and lithium disilicate have been becoming the most popular materials in the dentistry, due to their improved mechanical strengths (Conrad et al., 2007). For instance, among the 600 thousands all-ceramic restorations fabricated by Glidewell Laboratories in 2011, 75\% are Zirconia ceramics, 23\% are lithium disilicate and only less than $2 \%$ are leucite-reinforced other ceramics.

A strong and durable resin-ceramic bond improves marginal adaptation and provides high retention (Blatz et al., 2003). The resin-ceramic bonding procedure includes surface treatment/roughness (mechanical bonding) and/or priming (chemical bonding) and cementation with resin cements. Blatz et al. (2003) reviewed the resin-ceramic bonding based on the literature published from 1966-2001, while Conrad et al. (2007) have a systematic review covering all-ceramics, with respect to survival, material properties, cementation and clinical recommendation based on the literature published between 1996 and 2006. Thompson et al. (2011) reviewed the cementation to Zirconia based on the literatures published before 2009. During the past several years, new ceramic materials, such as IPS e. max Press lithium disilicate (Ivoclar Vivadent) (Conrad et al., 2007) and new bonding techniques/primers, such as phosphate-containing Zirconia primers, have been developed (Attia and Kern, 2011a; Ikemura et al., 2011a; Magne et al., 2010). This review will cover primarily the literature from 20082012, focusing on the latest resin bonding techniques (including surface treatment, priming and cementation) for dental all-ceramic materials, especially the two dominant materials Zirconia and lithium disilicate ceramics.

\section{MATERIALS AND METHODS}

A search of English peer-reviewed dental literature from PubMed and MEDLINE databases was conducted and limited to the publications between the years 2008 
and 2012. Key words included Zirconia, lithium disilicate and bond. Titles and abstracts of the articles listed from search results were reviewed and evaluated for appropriateness.

\section{RESULTS}

A total of 300 articles was identified through the literature search and 186 articles were published between 2008 and 2012. The abstracts of articles were reviewed and evaluated and a total of 101 articles were relevant to re-sign-ceramic bonding. The literature demonstrates that a variety of surface roughness, priming and cementation methods are available for improving resin-ceramic bonding.

\section{DISCUSSION}

Lithium disilicate and Zirconia ceramics: Lithium disilicate $\left(2 \mathrm{SiO}_{2}-\mathrm{Li}_{2} \mathrm{O}\right)$, such as IPS e. max (Ivoclar Vivadent) which is available as an ingot and block, can be processed using the lost-wax hot pressing techniques (ingot, IPS e. max press) or state-of-the-art computeraided design/computer-aided manufacturing (CAD/CAM) milling procedure (block, IPS e. $\max$ CAD) (Fasbinder et al., 2010). It can be used for anterior/posterior crowns, inlays/onlays, veneers, implants and fixed partial denture prosthesis frameworks The pre-crystallized blocks or ingots are milled to the desired form by CAD/CAM or pressing techniques and the final crystallization occurred at $850^{\circ} \mathrm{C}$ (CAD/CAM) or $920^{\circ} \mathrm{C}$ (Pressing) under vacuum (Fasbinder et al., 2010; Conrad et al., 2007). Lithium disilicate glass ceramics have improved physical properties compared to other glass ceramics. The IPS e. max glass ceramic has a flexural strength of 360-500 MPa, which is more than twice greater than that of other glass ceramic monolithic materials (Fasbinder et al., 2010).

Zirconia or Zirconium Oxide $\left(\mathrm{ZrO}_{2}\right)$, is a polymorphic white crystalline material that occurs in three crystallographic forms. It has a monoclinic crystal structure at room temperature, tetragonal between 1170 and the $2370^{\circ} \mathrm{C}$ and cubic structure above $2370^{\circ} \mathrm{C}$ (up to its melting point of $2680^{\circ} \mathrm{C}$ ) (Denry and Kelly, 2008). The phase transformations from cubic to tetragonal and from tetragonal to monoclinic occur upon cooling and are accompanied by volume expansions (2.3\% for cubic-to-tetragonal and $4.5 \%$ for tetragonal-tomonoclinic), which induce very large internal stresses. A small amount of lower valence oxide (e.g., Magnesium oxide, yttrium oxide, calcium oxide) is added to pure Zirconia to control the volume expansion and stabilize Zirconia in its tetragonal phase at room temperature (Conrad et al., 2007). Examples of dental zirconia include yttria $\left(\mathrm{Y}_{2} \mathrm{O}_{3}\right)$ stabilized tetragonal zirconia polycrystals (Y-TZP), which usually contain 3 mol\% of yttria as a stabilizer (3Y-TZP), such as Lava (3M ESPE), Cercon (Dentsply) and DC Zircon (DSC Precident), zirconia-toughened alumina (e.g. In-Ceram Zirconia, Vita) and magnesia partially stabilized Zirconia (e.g. Denzir-M, Dentronic AB). Y-TZP can be manufactured through CAD/CAM techniques. First, an enlarged framework is designed and milled from presintered soft block. Then the soft zirconia is sintered between 1350 and $1550^{\circ} \mathrm{C}$. The Zirconia framework has a linear shrinkage 20-25\% during the sintering (Conrad et al., 2007). Y-TZP has excellent mechanical properties, such as high flexural strength $(\sim 1000 \mathrm{MPa})$, high fracture toughness $\left(6-8 \mathrm{MPa} \mathrm{m} \mathrm{m}^{1 / 2}\right)$, low friction coefficient (0.028-0.082) (Szpiro et al., 2008). Dental Zirconia ceramics can be used for crowns, cores, posts, implants, onlays, fixed partial denture prosthesis frameworks.

\section{Surface Treatments:}

Silica-based ceramics: A reliable and effective resinceramic bond depends on mechanical and chemical bonding (Blatz et al., 2003) which are created through mechanical interlocking from surface roughening and from the chemical reaction of resin materials (e.g. Primers) and ceramics, respectively. Mechanical bonding/interlocking is created through infiltration of adhesive into highly micro-retentive substrates. Common surface treatment methods for creating microretentive ceramic surfaces include grinding, airabrasion with alumina, acid etching and the combinations of any of these methods.

For the glass ceramics which contain various amounts of glass/silica compositions, such as lithium disilicate, etching with $4-9.5 \%$ hydrofluoric acid has been proven a successful surface treatment method to provide surface roughness for mechanical interlocking/bonding (Blatz et al., 2003; Conrad et al., 2007). Among different surface treatments, such as phosphoric or HF acid etching and air-abrasion with alumina, etching with hydrofluoric acid was the most effective in enhancing the bond strength of resin material to lithium-disilicate ceramics (Nagai et al., 2005; Panah et al., 2008; Brum et al., 2011). Lithiumdisilicate IPS e. max CAD had the highest bond strength when it was the HF-etched after machined, compared to being machined only or machined/grit blasted (Pollington et al., 2010). It seemed that laser etching (Er: YAG laser; wavelength: $2940 \mathrm{~nm}$ ) with an appropriate power setting $(300 \mathrm{~mJ})$ could also be used for surface treatment of lithium disilicate and could be 
as effective as hydrofluoric acid etching (Gokce et al., 2007).

Contaminations, such as saliva, blood and hydrogen peroxide, influenced the bonding between dentin and lithium disilicate ceramics, while desensitize and disinfectant had no negative effects on the bond strengths (Zortuk et al., 2010). Among 4 different cleaning methods (etching with $37 \%$ phosphoric acid, etching 5\% hydrofluoric acid, 96\% isopropanol, air polishing device with sodium bicarbonate), re-etching with hydrofluoric acid is the most effective in removing lithium duplicates contamination with saliva and/or a silicone disclosing medium (Klosa et al., 2009). Hydrofluoric acid-etched silica-based ceramic has a highly retentive high-energy surface which is highly contaminable. The try-in pastes on etched ceramics (before silane treatment) are very difficult to remove. Studies on the efficacy of 'Try-in' paste removal showed all of etched lithium disilicates had remaining particles of try-in pastes, after cleaning by different methods, such as an ultrasonic bath in distilled water, air/water spray, etch with phosphoric acid plus an air / water spray, or etch with phosphoric acid before and after hydrofluoric acid application plus air/water spray (Prata et al., 2011).

Non-silica-based ceramics (Zirconia): Zirconia has a silica-free surface and HF-etching is not effective for changing Zirconia's morphology microstructure (Borges et al., 2003). Airborne particle abrasion with alumina or grinding creates surface roughening and significantly improved Zirconia-resin bond strength (Blatz et al., 2007). However, excess grinding or airabrasion might promote Zirconia degradation (Sato et $a l ., 2008)$. In recent years, many other surface treatment techniques have been explored to enhance resinZirconia bonding. Plasma or gas-fluorination effectively improved the ceramic-Zirconia bond strength, probably because it increased hydroxylation on the surface to allow for covalent bonding between Zirconia surface and resin cement (Piascik et al., 2011a; 2011b; 2012). Acidic treated with Piranha solution also created hydroxylation at Zirconia surface, which strongly increased the bond strength between zircon and resin cements, such as Multilink (Ivoclar Vivadent). However, it didn't improve MDP-containing resin cement, Panavia F2.0 (Kuraray) (Lohbauer et al., 2008). The laser treatments, such as erbium: yttriumaluminum-garnet (Er: YAG) Er: YAG and neodymium:: yttrium-aluminum-garnet (Nd: YAG) laser, significantly increased the bond strength of Zirconia, while CO (2) laser treatment was less effective for improving Zirconia bonding (Akin et al., 2011; 2012;
Paranhos et al., 2011). However, it was reported that the laser treatment, such as Er: YAG laser, did not result in a durable resin/Zirconia bond. The microshear bond strength was dropped significantly after 6 months water storage (Foxton et al., 2011). Selective Infiltration Etching (SIE) method used principles of heat-induced maturation and grain boundary diffusion to transform nonretentive Zirconia surfaces into a highly retentive surface, resulting in improved Zirconia-resin bond strengths (Aboushelib et al., 2007; 2008; 2009; 2010; Casucci et al., 2011; Mirmohammadi et al., 2010a). Nano-alumina coating, a non-invasive method, has been developed for Zirconia surface treatment. Hydrolysis of alumina nitride powder on Zirconia surface created a nano-alumina coating (240 nm thick) and a highly retentive Zirconia surface, significantly improving resin-Zirconia bond strength (Jevnikar et al., 2010). However, surface roughness of Zirconia without a following application of phosphatebased primer, might not be able to provide durable Zirconia-resin bond strength (Aboushelib et al., 2009).

Saliva contamination significantly affected resin bonds to Zirconia ceramic and its durability. After saliva contamination, X-ray Photoelectron Spectroscopy (XPS) revealed an organic coating on Zirconia. Cleaning with water rinsing, with isopropanol, or with phosphoric acid was not able to remove the contamination. Airborne-particle abrasion was the most effective cleaning method (Yang et al., 2008). On nanoalumina coated Zirconia surface, phosphoric acid cleaning was effective in removal of saliva contamination, but was not effective in the removal of the silicone disclosing agent (Zhang and Degrange, 2010). It was also reported that air abrasion at $0.05 \mathrm{MPa}$ and ultrasonic cleaning were able to improve resinZirconia bond strength and its durability (Attia and Kern, 2011b).

\section{Primers:}

Silica-based ceramics: Silane coupling agents or silanes in dentistry are organic compounds that contain polymerizable groups, such as (meth)acrylates, in one end and silane alkoxy groups in the other. The (meth) acrylate functional groups can polymerize with an organic matrix of dental resin materials (e.g., dental resin cements, composites, adhesives). The silane alkoxy group can react with a hydroxylated surface, like silica-based porcelain and ceramic via a chemical covalent bond Si-O-Si (Thompson et al., 2011; Blatz et al., 2003). Silane treatment after HF-etching remains the most effective method for improving resin bonding with silica-based ceramics (Panah et al., 2008; Nagai et al., 2005). Studies showed that phosphate-based 
primers (e.g., Metal/Zirconia Primer, Ivoclar Vivadent; Alloy Primer, Kuraray) which contained no silane were not effective to improve resin bond strength (bond strength was 0 on polished ceramic surface) on silicabased felds pathic ceramics. The primers containing only silane monomer was the most effective for improving resin bonding to silica-based ceramics (Queiroz et al., 2012). However, the primers which contained silane and other monomers (such as Clearfil Ceramic Primer which contained a silane and phosphate monomer), was not effective (bond strength was 0 on polished ceramics). It was probably because the extra resin monomer inhibited the condensation reaction between silanes and silica (Chen et al., 2011b).

Non-silica-based Zirconia ceramics: Silanes are commonly used for coupling with silica-based ceramics via the formation of chemical covalent bond ( $\mathrm{Si}-\mathrm{O}-\mathrm{Si}$ ), to achieve a chemical bonding between resin and ceramics. Zirconia ceramics have silica-free surface and possess relatively non-polar surface. It is more chemically stable than silica-based ceramics, so traditional silane chemistry is not usually effective for Zirconia (Thompson et al., 2011). In recent years, silica-coating techniques have been explored to convert silica-free into silica-rich zirconia surface, for utilizing the chemical bonding provided by silanation. Tribochemical silica coating (e.g., Rocatec or CoJet system, 3M ESPE) is a commonly used and commercial technique, which air-abrades Zirconia surface with alumina particles that have been coated with nano-silica, resulting the impregnation of nano-silica into the Zirconia surface. Studies showed tribochemical silicacoating followed by silanation significantly enhanced bond strengths between zirconia and resin materials (Xible et al., 2006; Ozcan et al., 2011; Passos et al., 2010), but it was not clear whether it was caused by silica-coating or the surface roughening effect of airabrasion. After silica-coating, different silence might have different effects on resin-Zirconia bond strengths. Silanation with the combination of functional (3acryloxypropyl)trimethoxysilane with cross-linking bis[3-(trimethoxysilyl)propyl]amine or glycidoxypropyltrimethoxysilane seemed to have higher bond strengths than other silanes (Lung et al., 2012; Matinlinna and Lassila, 2011)

Tribochemical silica-coating followed by a silane coupling agent application was originally designed for surface treatment of soft materials like metals. It is a clinically proved method to enhance the bonding of resin materials to dental metal materials (Matinlinna and Vallittu, 2007). However, Zirconia ceramics are densely sintered mechanically tough materials, which might be difficult to be coated by silica. Research studies showed that the tribochemical silicacoating/silanation had the same or similar effects as regular air-abrasion with alumina particles on improving zirconia-resin bond strengths, indicating tribochemical silica-coating provided only air-abrasion effect for creating surface roughness (Akyil et al., 2010; Re et al., 2008; Tanaka et al., 2008; Smith et al., 2011). It was reported that tribochemical silica-coating didn't provide stable resin-Zirconia bond strength (Kern and Wegner, 1998). The reason was probably that silica was not strongly attached to Zirconia surface. The EDXS analysis and SEM studies showed that the coating silica on Zirconia surface could be cleaned away by ultrasonication in water or pressurized water spray (Nishigawa et al., 2008; Chen et al., 2011a), indicating that no stable chemical bond was formed between silica and zirconia. The silica was probably deposited on the Zirconia surface via weak physical force, such as vander-Waals forces, which might not be strong and stable enough in a clinical situation. Further investigation into this technique would be necessary before a clinical recommendation is given.

Several other silica-coating techniques have been developed for Zirconia surface treatment in recent years. Pyrochemical modification modified Zirconia surface by utilizing flame treatment with tetraethoxy silane containing butane as fuel gas (Janda et al., 2003). In this process, six fragments were deposited onto the Zirconia surface via weak physical force (van-derWaals forces), resulting in weak bonding. Another method used the glazing techniques by applying thin coatings of acid-etchable glasses/porcelain on zirconia, followed by HF-etching and silane treatment. This technique resulted in a significantly enhanced resinZirconia bond strengths (Everson et al., 2012; Valentino et al., 2012; Fushiki et al., 2011; Ntala et al., 2010). The internal coating technique (INT) (Kitayama et al., 2009; 2010a) followed by silanation also improved Zirconia-resin bond strengths. Other silicacoating methods include gas-phase chloro-silane pretreatment (Piascik et al., 2009) and sol-gel process silica-coating (Zhang et al., 2009). Further investigations into these techniques are required before clinical recommendations.

In the past 5 years, bonding agents/primers (both commercial and experimental products) containing organo-phosphate monomers, such as 10Methacryloxydecyl Dihydrogen Phosphate (MDP), have been developed for improving bond strengths of resin materials to silica-free Zirconia surface (Tanaka et al., 2008; Magne et al., 2010). Studies have shown the commercial phosphate-monomer-containing-zirconia 
primers, such as Metal/Zirconia Primer (Ivoclar Vivadent), Monobond Plus (Ivoclar Vivadent), Clerafil Ceramic Primer (Kuraray), Signum Zirconia Bond (Heraeus), AZ Primer (Shofu) and ZPrime Plus (Bisco) significantly improved the initial and long-term resin bond strengths to zirconia ceramics (Cura et al., 2011; Azimian et al., 2011; Koizumi et al., 2012; Attia and Kern, 2011a; Ural et al., 2010; Takeuchi et al., 2010; Kitayama et al., 2010b; Lehmann and Kern, 2009; Magne et al., 2010). The metal primes that contain phosphate monomers, such as Alloy Primer (Kuraray), Estenia Opaque Primer (Kuraray) were also effective for improving bond strengths between zirconia and resin cements (Souza et al., 2011; Yun et al., 2010; Nakayama et al., 2010; Lehmann and Kern, 2009). Some newly designed experimental bonding agents which contained phosphate monomers, such as 6methacryloyloxyhexyl phosphonoacetate (6-MHPA), also showed strong adhesion to Zirconia ceramic materials (Ikemura et al., 2011a; 2011b; 2011c). It was reported that the surface treatment of a combination of air-abrasion and phosphate-monomer-containing primers improved the durability of Zirconia-resin bond strengths (Lindgren et al., 2008; Kern et al., 2009; Akgungor et al., 2008). Other studies showed the combination of an organophosphate monomer (e.g., MDP) with another functional monomer further improved Zirconia-resin bond strengths. For instance, ZPrime Plus which contains both organophosphate monomer and carboxylate monomer, had higher bond strength than other commercial Zirconia primers (Magne et al., 2010; Chen et al., 2011a; 2012; Piascik et al., 2012). The primers contain both MDP and a zirconate coupler, or contain both MDP and VBATDT (6-N-4-vinylbenzylpropylamino-1,3,5-triazine 2,4dithione) showed higher bond strengths than MDP alone (Yoshida et al., 2006; Souza et al., 2010).

The chemical structure of organo-phosphate monomer contains polymerizable functional groups and phosphoric acid (phosphate) groups. The polymerizable groups, such as (meth) acrylates, can copolymerize with the matrix of (meth) acrylate-based dental resin cements, composites and adhesives (e.g. BisGMAbased materials). The phosphoric acid groups have a strong adhesion to Zirconia ceramics. In recent years, the chemical bond formation (via $\mathrm{Zr}-\mathrm{O}-\mathrm{P}$ covalent bond) between phosphate monomers and Zirconia ceramics has been postulated (Yoshida et al., 2006). Studies with X-ray and NMR MAS ${ }^{31} \mathrm{P}$ confirmed that a stable chemical bond (Zr-O-P) between organophosphate (Octyl phosphate) and Zirconia was formed (Carriere et al., 2004). Later, it was confirmed by secondary ion mass spectrometry (SIMS) that ZPrime Plus, an MDP- containing zirconia primer, formed a chemical bond (Zr-O-P) with zirconia ceramics (Chen et al., 2012). ZPrime Plus showed stable resin-zirconia bond strength (bond strength value had no decrease after 2year aging) probably due to the chemical covalent bond (Zr-O-P) formation between zirconia and the primer (Chen et al. 2012).

Composite cements: After surface roughness and/or chemically priming of dental ceramics, resin based composite cements are used for luting of ceramic restorations (Blatz et al., 2003). Resin composite cements contain inorganic fillers and resin monomers, such as BisGMA, UDMA and TEGDMA. They have similar compositions as conventional restorative composites, but usually with a less amount of fillers and higher flowability. Traditional resin composite cements contain no adhesion functional monomer (e.g. phosphate-monomers) and require a separate ceramic primer (i.e. silane primers for silica-based ceramics and phosphate-monomer-containing primers for Zirconia) to achieve a strong adhesion between resin cements and ceramics. The film thickness of a resin cement might significantly affect the short-term and long-term bond strengths. It was reported that greater resin cement film thickness $(100 \mu \mathrm{m}$ vs. $50 \mu \mathrm{m})$ resulted in lower bond strength of resin materials to lithium disilicate ceramics (Cekic-Nagas et al., 2010). Another study showed the Zirconia bond strengths were significantly reduced when the resin cement layer was thick (Egilmez et al., 2012). Contrary to the research result, Lee et al. (2011) found that differences in cement thickness (40 or 160 $\mu \mathrm{m})$ did not influence the resin-Zirconia bond strength given the same cements and storage conditions.

In recent years, phosphate-monomer containing self-adhesive resin cements have been developed and commercialized. Examples of self-adhesive cements include BisCem (Bisco), G-Cem (GC), Clearfil SA Cement (Kuraray), RelyX Unicem (3M ESPE) and MaxCem (Kerr). Phosphate-monomers were effective agents for improving Zirconia bonding, but not effective for improving resin bonding to silica-based ceramics. It was reported that traditional resin cements had a better bonding efficacy and more durable bond strength than self-adhesive resin cements to the lithium disilicate glass ceramics (Hooshmand et al., 2012; Luhrs et al., 2010; Kumbuloglu et al., 2005), probably because self-adhesive cements had weaker physical properties than conventional resin cements. Due to the phosphate monomers they contain, self-adhesive cements or phosphate-monomer-containing resin cements usually had mild bond strengths to Zirconia ceramics even without a separate primer treatment 
(Yang et al., 2010; Luthy et al., 2006; Blatz et al., 2010; Osorio et al., 2012; Miragaya et al., 2011; Mirmohammadi et al., 2010b; Nakamura et al., 2010). However, the bond strengths of self-adhesive cements were usually weak, compared to traditional resin cements with Zirconia primers (Nothdurft et al., 2009; Zhang et al., 2010a). The bond strength of self-adhesive cements on Zirconia could be improved by application of phosphate-monomer-containing primers (Zhang et al., 2010b; Cavalcanti et al., 2009). Compared to traditional resin cements, self-adhesive resin cements usually have weaker physical properties, are more hydrophilic, have higher water sorption and tends to faster hydrolytic degradation. Research showed phosphate-monomer containing Panavia F2.0 (Kuraray) had no adhesion $(0 \mathrm{MPa})$ on the Zirconia after 6,000 thermal cyclings (Ozcan et al., 2008). The bond strength of self-adhesive cement RelyX UniCem (3M ESPE) was significantly affected by thermocycling aging, while the bond strength of traditional resin cements did not significantly change after aging (D'Amario et al., 2010). Another problem of selfadhesive resin cements are that they usually had poor self-cure ability (10.8-24.9\% degree of conversion in self-cure mode) (Vrochari et al., 2009). In the situation of opaque ceramics such as lithium disilicates or Zirconia ceramics, self-curing plays a critical role in clinical restorations. Vrochari et al. (2009) stated that "The low \%DC found raises questions as to whether these materials can be successfully used in clinical applications".

Resin modified glass ionomer cement, a restorative material based on the reaction of silicate glass powder and polyalkenoic acid, is occasionally used for Zirconia cementations. However, due to its weak physical properties and lack of phosphate-monomer, it had an even poorer bond strength than a self-adhesive cement to Zirconia (Peutzfeldt et al., 2011; Kim et al., 2011; Attia, 2011). The (resin-modified) glass ionomer cements, such as Fuji I and Ketac Cem yielded nearzero or zero bond strength values (lower than selfadhesive cement Panavia 2.0) on Zirconia after thermocycling. All debonded specimens showed adhesive failure (Kim et al., 2011). Another study also showed resin-reinforced glass-ionomer cement, such as RelyX Luting (3M ESPE) and Fuji Plus, could not offer a stable bond to air-abraded Zirconia ceramic after thermocycling (60-70\% bond strength decrease after 20000 times of thermocycling) (Zhang et al., 2010a). It was reported that zinc phosphate cement had an even lower bond strength of Zirconia than resin modified glass ionomer cements (Uo et al., 2006).

\section{CONCLUSION}

The resin bond to silica-based ceramics, like lithium disilicates, is well documented. Preferred bonding methods are hydrofluoric acid-etching and subsequent silane treatments. The preferred protocol for resin bond to Zirconia is the combination of surface roughness and treatment with a phosphate-containing Zirconia primer followed by cementation with hydrophobic non-phosphate-containing resin cement.

\section{REFERENCES}

Aboushelib, M.N., A.J. Feilzer and C.J. Kleverlaan, 2010. Bonding to Zirconia using a new surface treatment. J. Prosthodont., 19: 340-346. DOI: 10.1111/j.1532-849X.2010.00575.x

Aboushelib, M.N., C.J. Kleverlaan and A.J. Feilzer, 2007. Selective infiltration-etching technique for a strong and durable bond of resin cements to Zirconia-based materials. J. Prosthet. Dent., 98: 379-388. DOI: 10.1016/S0022-3913(07)60123-1

Aboushelib, M.N., H. Mirmohamadi, J.P. Matinlinna, E. Kukk and H.F. Ounsi et al., 2009. Innovations in bonding to Zirconia-based materials. Part II: Focusing on chemical interactions. Dent. Mater., 25:989-993. DOI: 10.1016/j.dental.2009.02.011

Aboushelib, M.N., J.P. Matinlinna, Z. Salameh and H. Ounsi, 2008. Innovations in bonding to Zirconiabased materials: Part I. Dent. Mater., 24: 12681272. DOI: $10.1016 /$ j.dental.2008.02.010

Akgungor, G., D. Sen and M. Aydin, 2008. Influence of different surface treatments on the short-term bond strength and durability between a Zirconia post and a composite resin core material. J. Prosthet. Dent., 99: 388-399. DOI: 10.1016/S0022-3913(08)60088-8

Akin, H., F. Tugut, G.E. Akin, U. Guney and B. Mutaf, 2012. Effect of Er:YAG laser application on the shear bond strength and microleakage between resin cements and Y-TZP ceramics. Lasers Med. Sci., 27: 333-338. DOI: 10.1007/s10103-011-0883-4

Akin, H., Z. Ozkurt, O. Kirmalı, E. Kazazoglu and A.K. Ozdemir, 2011. Shear bond strength of resin cement to Zirconia ceramic after aluminum oxide sandblasting and various laser treatments. Photomed. Laser Surg., 29: 797-802. DOI: 10.1089/pho.2011.3039

Akyil, M.S., I.H. Uzun and F. Bayindir, 2010. Bond strength of resin cement to yttrium-stabilized tetragonal Zirconia ceramic treated with air abrasion, silica coating and laser irradiation. Photomed. Laser Surg., 28: 801-808. DOI: 10.1089/pho.2009.2697 
Attia, A. and M. Kern, 2011a. Long-term resin bonding to Zirconia ceramic with a new universal primer. J. Prosthet. Dent., 106: 319-327. DOI: 10.1016/S0022-3913(11)60137-6

Attia, A. and M. Kern, 2011b. Effect of cleaning methods after reduced-pressure air abrasion on bonding to Zirconia ceramic. J. Adhes. Dent., 13: 561-567. DOI: 10.3290/j.jad.a19831

Attia, A., 2011. Bond strength of three luting agents to zirconia ceramic-influence of surface treatment and thermocycling. J. Applied Oral Sci., 19: 388-395. PMID: 21710091

Azimian, F., K. Klosa and M. Kern, 2011. Evaluation of a new universal primer for ceramics and alloys. J. Adhes Dent. DOI: 10.3290/j.jad.a22193 PMID: 22043473

Blatz, M.B., A. Sadan and M. Kern, 2003. Resinceramic bonding: A review of the literature. J. Prosthet. Dent., 89: 268-274. DOI: 10.1067/mpr.2003.50

Blatz, M.B., G. Chiche, S. Holst and A. Sadan, 2007. Influence of surface treatment and simulated aging on bond strengths of luting agents to zirconia. Quintessence Int., 38: 745-753. PMID: 17873981

Blatz, M.B., J.H. Phark, F. Ozer, F.K. Mante and N. Saleh et al., 2010. In vitro comparative bond strength of contemporary self-adhesive resin cements to zirconium oxide ceramic with and without air-particle abrasion. Clin. Oral Investig., 14: 187-192. DOI: $10.1007 / \mathrm{s} 00784-009-0278-0$

Borges, G.A., A.M. Sophr, M.F.D. Goes, L.C. Sobrinho and D.C.N. Chan, 2003. Effect of etching and airborne particle abrasion on the microstructure of different dental ceramics. J. Prosthet. Dent., 89: 479-488. DOI: 10.1016/S0022-3913(02)52704-9

Brum, R., R. Mazur, J. Almeida, G. Borges and D. Caldas, 2011. The influence of surface standardization of lithium disilicate glass ceramic on bond strength to a dual resin cement. Oper. Dent., 36: 478-485. DOI: 10.2341/11-009-L

Carriere, D., M. Moreau, P. Barboux and J.P. Boilot, 2004. Modification of the surface properties of porous nanometric Zirconia particles by covalent grafting. Langmuir, 20: 3449-3455. DOI: $10.1021 / \mathrm{la} 036249 \mathrm{~m}$

Casucci, A., F. Monticelli, C. Goracci, C. Mazzitelli and A. Cantoro et al., 2011. Effect of surface pretreatments on the Zirconia ceramic-resin cement microtensile bond strength. Dent. Mater., 27: 10241030. PMID: 21798589

Cavalcanti, A.N., R.M. Foxton, T.F. Watson, M.T. Oliveira and M. Giannini et al., 2009. Bond strength of resin cements to a Zirconia ceramic with different surface treatments. Oper. Dent., 34: 280-287. DOI: $10.2341 / 08-80$
Cekic-Nagas, I., S. Canay and E. Sahin, 2010. Bonding of resin core materials to lithium disilicate ceramics: the effect of resin cement film thickness. Int. J. Prosthodont., 23: 469-471. PMID: 20859565

Chen, L., B. Suh, D. Brown and X. Chen, 2012. Bonding investigation of prime Zirconia ceramics for evidence of chemical bonding and improved bond strengths. Am. J. Dent., In Press.

Chen, L., B.I. Suh, J. Kim and F.R. Tay, 2011a. Evaluation of silica-coating techniques for Zirconia bonding. Am. J. Dent., 24: 79-84. PMID: 21698986

Chen, L., G. Alex, T. Brown, A. Suh, D. Brown and B. Suh, 2011b. Priming Efficacy of Three Types of Silane Primers. J. Dent. Res.

Conrad, H.J., W.J. Seong and I.J. Pesun, 2007. Current ceramic materials and systems with clinical recommendations: A systematic review. J. Prosthet. Dent., 98: 389-404. DOI: 10.1016/S00223913(07)60124-3

Cura, C., M. Ozcan, G. Isik and A. Saracoglu, 2011. Comparison of alternative adhesive cementation concepts for Zirconia ceramic: Glaze layer vs Zirconia primer. J. Adhes. Dent., 14: 75-82. DOI: 10.3290/j.jad.a21493

D'Amario, M., M. Campidoglio, A.L. Morresi, L. Luciani and E. Marchetti et al., 2010. Effect of thermocycling on the bond strength between dualcured resin cements and zirconium-oxide ceramics. J. Oral Sci., 52: 425-430. DOI: 10.2334/josnusd.52.425

Denry, I. and J.R. Kelly, 2008. State of the art of Zirconia for dental applications. Dent. Mater., 24: 299-307. DOI: 10.1016/j.dental.2007.05.007

Egilmez, F., G. Ergun, I. Cekic-Nagas, P.K. Vallittu and L.V. Lassila, 2012. Influence of cement thickness on the bond strength of tooth-colored posts to root dentin after thermal cycling. Acta. Odontol. Scand. In Press. DOI: 10.3109/00016357.2011.654257

Everson, P., O. Addison, W.M. Palin and F.J.T. Burke, 2012. Improved bonding of Zirconia substructures to resin using a "glaze-on" technique. J. Dent., 40: 347-351. DOI: 10.1016/j.jdent.2011.12.011

Fasbinder, D.J., J.B. Dennison, D. Heys and G Neiva, 2010. A clinical evaluation of chairside lithium disilicate CAD/CAM crowns: A two-year report. JADA, 141: 10S-14S.

Foxton, R.M., A.N. Cavalcanti, M. Nakajima, P. Pilecki and M. Sherriff et al., 2011. Durability of resin cement bond to aluminium oxide and zirconia ceramics after air abrasion and laser treatment. J. Prosthodont., 20: 84-92. DOI: 10.1111/j.1532849X.2010.00678. $\mathrm{x}$ 
Fushiki, R., F. Komine, M.B. Blatz, M. Koizuka and K. Taguchi et al., 2011. Shear bond strength between an indirect composite layering material and feldspathic porcelain-coated Zirconia ceramics. Clin. Oral. Investing. In Press. DOI: 10.1007/s00784-011-0641-9

Gokce, B., B. Ozpinar, M. Dundar, E. Comlekoglu and B.H. Sen et al., 2007. Bond strengths of allceramics: Acid vs laser etching. Oper. Dent., 32: 173-178. DOI: 10.2341/06-52

Hooshmand, T., G. Rostami, M. Behroozibakhsh, M. Fatemi and A. Keshvad et al., 2012. Interfacial fracture toughness of different resin cements bonded to a lithium disilicate glass ceramic. J. Dent., 40: 139-145. DOI: 10.1016/j.jdent.2011.12.005

Ikemura, K., H. Tanaka, T. Fujii, M. Deguchi and N. Negoro et al., 2011c. Design of a new, multipurpose, light-curing adhesive comprising a silane coupling agent, acidic adhesive monomers and dithiooctanoate monomers for bonding to varied metal and dental ceramic materials. Dent. Mater. J., 30: 493-500. DOI: 10.4012/dmj.2011-012

Ikemura, K., H. Tanaka, T. Fujii, M. Deguchi and T. Endo et al., 2011a. Development of a new singlebottle multi-purpose primer for bonding to dental porcelain, alumina, Zirconia, and dental gold alloy. Dent. Mater. J., 30: 478-484. DOI: 10.4012/dmj.2010-182

Ikemura, K., Y. Jogetsu, K. Shinno, T. Nakatsuka and T. Endo et al., 2011b. Effects of a newly designed HEMA-free, multi-purpose, single-bottle, selfetching adhesive on bonding to dental hard tissues, zirconia-based ceramics and gold alloy. Dent. Mater. J., 30: 616-625. PMID: 21946481

Janda, R., J.F. Roulet, M. Wulf and H.J. Tiller, 2003. A new adhesive technology for all-ceramics. Dent. Mater. 19: 567-573. DOI: 10.1016/S01095641(02)00106-9

Jevnikar, P., K. Krnel, A. Kocjan, N. Funduk and T. Kosmac, 2010. The effect of nano-structured alumina coating on resin-bond strength to Zirconia ceramics. Dent. Mater. 26: 688-696. DOI: 10.1016/j.dental.2010.03.013

Kern, M. and S.M. Wegner, 1998. Bonding to Zirconia ceramic: Adhesion methods and their durability. Dent. Mater., 14: 64-71. DOI: 10.1016/S01095641(98)00011-6

Kern, M., A. Barloi and B. Yang, 2009. Surface conditioning influences Zirconia ceramic bonding. J. Dent. Res., 88: 817-822. DOI: $10.1177 / 0022034509340881$
Kim, M.J., Y.K. Kim, K.H. Kim and T.Y. Kwon, 2011. Shear bond strengths of various luting cements to zirconia ceramic: Surface chemical aspects. J. Dent., 39: 795-803. DOI: 10.1016/j.jdent.2011.08.012

Kitayama, S., T. Nikaido, R. Maruoka, L. Zhu and M. Ikeda et al., 2009. Effect of an internal coating technique on tensile bond strengths of resin cements to Zirconia ceramics. Dent. Mater. J., 28: 446-453. DOI: 10.4012/dmj.28.446

Kitayama, S., T. Nikaido, M. Ikeda, S. Alireza and H. Miura et al., 2010a. Internal coating of zirconia restoration with silica-based ceramic improves bonding of resin cement to dental zirconia ceramic. Biomed. Mater. Eng., 20: 77-87. DOI: 10.3233/BME-2010-0617

Kitayama, S., T. Nikaido, R. Takahashi, L. Zhu and M. Ikeda et al., 2010b. Effect of primer treatment on bonding of resin cements to Zirconia ceramic. Dent. Mater., 26: 426-432. DOI: 10.1016/j.dental.2009.11.159

Klosa, K., S. Wolfart, F. Lehmann, H.J. Wenz and M. Kern, 2009. The effect of storage conditions, contamination modes and cleaning procedures on the resin bond strength to lithium disilicate ceramic. J. Adhes. Dent., 11: 127-135. DOI: 10.3290/j.jad.a15324

Koizumi, H., D. Nakayama, F. Komine, M.B. Blatz and H. Matsumura, 2012. Bonding of resin-based luting cements to Zirconia with and without the use of ceramic priming agents. J. Adhes. Dent., In Press. DOI: $10.3290 /$ j.jad.a22711

Kumbuloglu, O., L.V.J. Lassila, A. User, S. Toksavul and P.K. Vallittu, 2005. Shear bond strength of composite resin cements to lithium disilicate ceramics. J. Oral Rehabil., 32: 128-133. DOI: 10.1111/j.1365-2842.2004.01400.x

Lee, T.H., J.S. Ahn, J.S. Shim, C.H. Han and S.J. Kim, 2011. Influence of cement thickness on resin-zirconia microtensile bond strength. J. Adv. Prosthodont., 3: 119-125. DOI: 10.4047/jap.2011.3.3.119

Lehmann, F. and M. Kern, 2009. Durability of resin bonding to Zirconia ceramic using different primers. J. Adhes. Dent., 11: 479-483. PMID: 20011768

Lindgren, J., J. Smeds and G. Sjogren, 2008. The effect of surface treatments and aging in water on bond strength to Zirconia. Oper. Dent., 33: 675-681. DOI: $10.2341 / 08-12$

Lohbauer, U., M. Zipperle, K. Rischka, A. Petschelt and F.A. Muller, 2008. Hydroxylation of dental Zirconia surfaces: Characterization and bonding potential. J. Biomed. Mater. Res. Part B: Applied Biomater., 87B: 461-467. DOI: 10.1002/jbm.b.31126 
Luhrs, A.K., S. Guhr, H. Gunay and W. Geurtsen, 2010. Shear bond strength of self-adhesive resins compared to resin cements with etch and rinse adhesives to enamel and dentin in vitro. Clin. Oral Investig., 14: 193-199. DOI: 10.1007/s00784-0090279-z

Lung, C.Y.K., E. Kukk and J.P. Matinlinna, 2012. Shear bond strength between resin and zirconia with two different silane blends. Acta. Odontol. Scand., In Press. DOI: 10.3109/00016357.2011.630014

Luthy, H., O. Loeffel and C.H.F. Hammerle, 2006. Effect of thermocycling on bond strength of luting cements to Zirconia ceramic. Dent. Mater., 22: 195-200. DOI: 10.1016/j.dental.2005.04.016

Magne, P., M.P.G. Paranhos and L.H. Burnett, 2010. New Zirconia primer improves bond strength of resin-based cements. Dent. Mater., 26: 345-352. DOI: 10.1016/j.dental.2009.12.005

Matinlinna, J.P. and L.V. Lassila, 2011. Enhanced resin-composite bonding to Zirconia framework after pretreatment with selected silane monomers. Dent. Mater., 27: 273-280. DOI: 10.1016/j.dental.2010.11.002

Matinlinna, J.P. and P.K. Vallittu, 2007. Silane based concepts on bonding resin composite to metals. J. Contemp. Dent. Pract., 8: 1-8. PMID: 17277821

Miragaya, L., L.C. Maia, C.E. Sabrosa, M.F.D. Goes and E.M.D. Silva, 2011. Evaluation of selfadhesive resin cement bond strength to yttriastabilized Zirconia ceramic (Y-TZP) using four surface treatments. J. Adhes. Dent., 13: 473-480. DOI: $10.3290 /$ j.jad.a19820

Mirmohammadi, H., M.N. Aboushelib, Z. Salameh, C.J. Kleverlaan and A.J. Feilzer, 2010a. Influence of enzymatic and chemical degradation on zirconia resin bond strength after different surface treatments. Am. J. Dent., 23: 327-330. PMID: 21344831

Mirmohammadi, H., M.N. Aboushelib, Z. Salameh, A.J. Feilzer and C.J. Kleverlaan, 2010b. Innovations in bonding to Zirconia based ceramics: Part III. Phosphate monomer resin cements. Dent. Mater., 26: 786-792. DOI: 10.1016/j.dental.2010.04.003

Nagai, T., Y. Kawamoto, Y. Kakehashi and H. Matsumura, 2005. Adhesive bonding of a lithium disilicate ceramic material with resin-based luting agents. J. Oral. Rehabil., 32: 598-605. DOI: 10.1111/j.1365-2842.2005.01464.x

Nakamura, T., K. Wakabayashi, S. Kinuta, H. Nishida and M. Miyamae et al., 2010. Mechanical properties of new self-adhesive resin-based cement. J. Prosthodont. Res., 54: 59-64. DOI: 10.1016/j.jpor.2009.09.004
Nakayama, D., H. Koizumi, F. Komine, M.B. Blatz and N. Tanoue et al., 2010. Adhesive bonding of Zirconia with single-liquid acidic primers and a trin-butylborane initiated acrylic resin. J. Adhes. Dent., 12: 305-310. DOI: 10.3290/j.jad.a17549

Nishigawa, G., Y. Maruo, M. Irie, M. Oka and K. Yoshihara et al., 2008. Ultrasonic cleaning of silica-coated zirconia influences bond strength between zirconia and resin luting material. Dent. Mater. J., 27: 842-848. PMID: 19241694

Nothdurft, F.P., P.J. Motter and P.R. Pospiech, 2009. Effect of surface treatment on the initial bond strength of different luting cements to zirconium oxide ceramic. Clin. Oral Investig., 13: 229-235. DOI: 10.1007/s00784-008-0222-8

Ntala, P., X. Chen, J. Niggli and M. Cattell, 2010. Development and testing of multi-phase glazes for adhesive bonding to Zirconia substrates. J. Dent., 38: 773-781. DOI: 10.1016/j.jdent.2010.06.008

Osorio, R., R.C.D. Oyague, F. Monticelli, E. Osorio and M. Toledano, 2012. Resistance to bond degradation between dual-cure resin cements and pre-treated sintered CAD-CAM dental ceramics. Med. Oral Patol. Oral Cir. Bucal. In Press. DOI: 10.4317/medoral.17828

Ozcan, M., C. Cura and L.F. Valandro, 2011. Early bond strength of two resin cements to Y-TZP ceramic using MPS or MPS/4-META silanes. Odontology, 99: 62-67. DOI: 10.1007/s10266-0100144-1

Ozcan, M., S. Kerkdijk and L.F. Valandro, 2008. Comparison of resin cement adhesion to Y-TZP ceramic following manufacturers' instructions of the cements only. Clin. Oral Investig., 12: 279-282. DOI: 10.1007/s00784-007-0151-y

Panah, F.G., S.M. Rezai and L. Ahmadian, 2008. The influence of ceramic surface treatments on the micro-shear bond strength of composite resin to IPS Empress 2. J. Prosthodont., 17: 409-414. DOI: 10.1111/j.1532-849X.2007.00296.x

Paranhos, M.P., L.H. Burnett Jr. and P. Magne, 2011. Effect of Nd: YAG laser and CO2 laser treatment on the resin bond strength to Zirconia ceramic. Quintessence Int., 42: 79-89. PMID: 21206937

Passos, S.P., L.G. May, D.C. Barca, M. Ozcan and M.A. Bottino et al., 2010. Adhesive quality of selfadhesive and conventional adhesive resin cement to Y-TZP ceramic before and after aging conditions. Oper. Dent., 35: 689-696. PMID: 21180009

Peutzfeldt, A., A. Sahafi and S. Flury, 2011. Bonding of restorative materials to dentin with various luting agents. Oper. Dent., 36: 266-273. DOI: $10.2341 / 10-236-\mathrm{L}$ 
Piascik, J.R., S.D. Wolter and B.R. Stoner, 2011a. Enhanced bonding between YSZ surfaces using a gas-phase fluorination pretreatment. J. Biomed. Mater. Res. B Applied Biomater., 98: 114-119. DOI: $10.1002 /$ jbm.b.31840

Piascik J.R., S.D. Wolter and B.R. Stoner, $2011 \mathrm{~b}$. Development of a novel surface modification for improved bonding to Zirconia. Dent. Mater., 27: e99-e105. DOI: 10.1016/j.dental.2011.01.005

Piascik, J.R., E.J. Swift, J.Y. Thompson, S. Grego and B.R. Stoner, 2009. Surface modification for enhanced silanation of Zirconia ceramics. Dent. Mater. 25: 1116-1121. DOI: 10.1016/j.dental.2009.03.008

Piascik, J.R., E.J. Swift, K. Braswell and B.R. Stoner, 2012. Surface fluorination of Zirconia: Adhesive bond strength comparison to commercial primers. Dent. Mater. 28: 604-608. DOI: 10.1016/j.dental.2012.01.008

Pollington, S., A. Fabianelli and R.V. Noort, 2010. Microtensile bond strength of a resin cement to a novel fluorcanasite glass-ceramic following different surface treatments. Dent. Mater., 26: 864872. DOI: 10.1016/j.dental.2010.04.011

Prata, R.A., V.P.D. Oliveira, F.C.H.D. Menezes, G.A. Borges and O.S.D. Andrade et al., 2011. Effect of 'Try-in' paste removal method on bond strength to lithium disilicate ceramic. J. Dent., 39: 863-870. DOI: 10.1016/j.jdent.2011.09.011

Queiroz, J.R., R.O. Souza, L.N. Junior Jr., M. Ozcan and M.A. Bottino, 2012. Influence of acid-etching and ceramic primers on the repair of a glass ceramic. Gen. Dent., 60: e79-e85. PMID: 22414522

Re, D., D. Augusti, I. Sailer, D. Spreafico and A. Cerutti, 2008. The effect of surface treatment on the adhesion of resin cements to Y-TZP. Eur. J. Esthet. Dent., 3: 186-196. PMID: 19655531

Sato, H., K. Yamada, G. Pezzotti, M. Nawa and S. Ban, 2008. Mechanical properties of dental Zirconia ceramics changed with sandblasting and heat treatment. Dent. Mater. J., 27: 408-414. DOI: 10.4012/dmj. 27.408

Smith, R.L., C. Villanueva, J.K. Rothrock, C.E. GarciaGodoy and B.R. Stoner et al., 2011. Long-term microtensile bond strength of surface modified Zirconia. Dent. Mater., 27: 779-785. DOI: 10.1016/j.dental.2011.03.018

Souza, G.M.D.D., N.R.F.A. Silva, L.A.M.S. Paulillo, M.F.D. Goes and E.D. Rekow et al., 2010. Bond strength to high-crystalline content Zirconia after different surface treatments. J. Biomed. Mater. Res. B Applied Biomater., 93B: 318-323. DOI: 10.1002/jbm.b.31549
Souza, G.M.D.D., V.P. Thompson and R.R. Braga, 2011. Effect of metal primers on microtensile bond strength between zirconia and resin cements. J. Prosthet. Dent., 105: 296-303. DOI: 10.1016/S0022-3913(11)60055-3

Szpiro, L., J.B. Park and N.M. Kumar, 2008. Bioceramics: Properties, Characterizations and Applications. 1st Edn., Springer, Berlin, ISBN: 0387095446, pp: 359.

Takeuchi, K., A. Fujishima, A. Manabe, S. Kuriyama and Y. Hotta et al., 2010. Combination treatment of tribochemical treatment and phosphoric acid ester monomer of Zirconia ceramics enhances the bonding durability of resin-based luting cements. Dent. Mater. J., 29: 316-323. PMID: 20484831

Tanaka, R., A. Fujishima, Y. Shibata, A. Manabe and Y. Miyazaki, 2008. Cooperation of phosphate monomer and silica modification on Zirconia. J. Dent. Res., 87: 666-670. DOI: 10.1177/154405910808700705

Thompson, J.Y., B.R. Stoner, J.R. Piascik and R. Smith, 2011. Adhesion/cementation to Zirconia and other non-silicate ceramics: Where are we now? Dent. Mater., 27: 71-82. DOI: 10.1016/j.dental.2010.10.022

Uo, M., G. Sjogren, A. Sundh, M. Goto and F. Watar et al., 2006. Effect of surface condition of dental Zirconia ceramic (Denzir) on bonding. Dent. Mater. J., 25: 626-631. DOI: 10.4012/dmj.25.626

Ural, C., T. Kulunk, S. Kulunk, M. Kurt and S. Baba, 2010. Determination of resin bond strength to Zirconia ceramic surface using different primers. Acta. Odontol. Scand., 69: 48-53. PMID: 20873994

Valentino, T.A., G.A. Borges, L.H. Borges, J.A. Platt and L. Correr-Sobrinho, 2012. Influence of glazed Zirconia on dual-cure luting agent bond strength. Oper. Dent., 37: 181-187. DOI: 10.2341/10-220-L

Vrochari, A.D., G. Eliades, E. Hellwig and K.T. Wrbas, 2009. Curing efficiency of four self-etching, selfadhesive resin cements. Dent. Mater., 25: 11041108. DOI: 10.1016/j.dental.2009.02.015

Xible, A.A., R.R.D.J. Tavarez, C.D.R.P.D. Araujo and W.C. Bonachela, 2006. Effect of silica coating and silanization on flexural and composite-resin bond strengths of Zirconia posts: An in vitro study. J. Prosthet. Dent., 95: 224-229. DOI: 10.1016/j.prosdent.2005.12.010

Yang, B., A. Barloi and M. Kern, 2010. Influence of air-abrasion on Zirconia ceramic bonding using an adhesive composite resin. Dent. Mater., 26: 44-50. DOI: 10.1016/j.dental.2009.08.008 
Yang, B., H.C. Lange-Jansen, M. Schoenberg, S. Wolfart and K. Ludwig et al., 2008. Influence of saliva contamination on Zirconia ceramic bonding. Dent. Mater., 24: 508-513. DOI: 10.1016/j.dental.2007.04.013

Yoshida, K., Y. Tsuo and M. Atsuta, 2006. Bonding of dual-cured resin cement to Zirconia ceramic using phosphate acid ester monomer and zirconate coupler. J. Biomed. Mater. Res. Part B: Applied Biomater., 77B: 28-33. DOI: 10.1002/jbm.b.30424

Yun, J.Y., S.R. Ha, J.B. Lee and S.H. Kim, 2010. Effect of sandblasting and various metal primers on the shear bond strength of resin cement to Y-TZP ceramic. Dent. Mater., 26: 650-658. PMID: 20427080

Zhang, C. and M. Degrange, 2010. Shear bond strengths of self-adhesive luting resins fixing dentine to different restorative materials. J. Biomater. Sci. Polym. Edn., 21: 593-608. DOI: 10.1163/156856209X431640
Zhang, S., A. Kocjan, F. Lehmann, T. Kosmac and M. Kern, 2010a. Influence of contamination on resin bond strength to nano-structured alumina-coated Zirconia ceramic. Eur. J. Oral Sci., 118: 396-403. DOI: $10.1111 / \mathrm{j} .1600-0722.2010 .00752 . \mathrm{x}$

Zhang, W., S.I. Masumi and X.M. Song, 2010 b. Bonding property of two resin-reinforced glassionomer cements to Zirconia ceramics. Quintessence Int., 41: e132-e140. PMID: 20614036

Zhang, X.F., H. Zheng and D.W. Han, 2009. Effect of nano-silica coating on bonding strength of Zirconia ceramics to dentin. Shanghai Kou Qiang Yi Xue, 18: 198-202. PMID: 19418000

Zortuk, M., K. Kilic, A.G. Gurbulak, B. Kesim and S. Uctasli, 2010. Tensile bond strength of a lithiumdisilicate pressed glass ceramic to dentin of different surface treatments. Dent. Mater. J., 29: 418-424. DOI: 10.4012/dmj.2009-074 